\title{
Overheating risk of a typical Norwegian residential building retrofitted to higher energy standards under future climate conditions
}

\author{
Zhiyong Tian $^{1 *}$ and Bozena Dorota Hrynyszyn ${ }^{1}$ \\ ${ }^{1}$ Department of Civil and Environmental Engineering, Norwegian University of Science and Technology, 7491 Trondheim, Norway
}

\begin{abstract}
Heat waves had attacked Norway in 2018 and 2019. Residents in Norway experienced a very uncomfortable indoor environment in the summer of 2018 and 2019. Few publications on the overheating risk of a typical Norwegian residential building under future climate change conditions were found. The typical Norwegian residential building retrofitted according to the minimum Norwegian energy requirements in the Norwegian Building Act of 2010 (Pbl2010/TEK17) and the international EnerPHit Standard was modelled in this study. Overheating risk of the typical residential building was simulated by Energy Plus engine via Ladybug and Honeybee plugins based on the Grasshopper. Overheating hours of the studied rooms under present-day, the 2050s and the 2080s weather conditions were shown. Too good airtightness does increase the overheating risk of the building when retrofitted to higher energy standards. It was found in this study that better insulation does reduce the overheating hours of the bedrooms slightly. This may be caused by low g-value of the windows based on recommendation according to the EnerPHit Standard. Overheating should be paid more attention in term of the expected future climate conditions. These results can provide some references to the buildings retrofitted to high-performance buildings.
\end{abstract}

\section{Introduction}

Since Energy Performance of Buildings Directive (EPBD) was published in 2010, energy efficient buildings become a hot research topic in Europe. All new buildings must be nearly zero-energy buildings by 31 December 2020. In the June 2018, the revised Energy Performance of Buildings Directive (2018/844/EU) was published. Health and well-being of building users was promoted under the new revised directive.

Energy-saving potential of a typical Norwegian residential building retrofitted according to the minimum Norwegian energy requirements in the Norwegian Building Act of 2010 (Pbl2010/TEK17) and the international EnerPHit Standard was analysed.

Heat waves attacked Norway in 2018 and 2019. Extreme heat waves seem to take place more and more frequently in the near future. Residents in Norway experienced a very uncomfortable indoor environment in the summer of 2018 and 2019. In addition, airconditioners or electrical fans have been installed in few residential buildings in Norway until now. The hot summer could cause serious health problems [1]. Few publications on indoor comfort conditions in Norwegian residential buildings under future climate conditions were found.

Li et al. [2] investigated the indoor overheating risk and mitigation strategies of converted lofts in London, UK. They found that passive adaptations were not capable of eliminating overheating entirely, and by the 2080 s active cooling was likely to be required to maintain comfortable indoor conditions in lofts. Grussa et al. [3] evaluated passive mitigation methods of reducing overheating risk through the use of solar shading combined with night-time ventilation based on a case study. They recommended that the interrelationship between glazing, shading, and ventilation (amongst other variables) need to be collectively evaluated at the planning stage to ensure the appropriate design of an effective management strategy. Salem et al. [4] carried out the investigation on the impacts of a changing climate on the overheating risk and energy performance for a village in United Kingdom (UK) adapted to the nZEB standards. They found that the buildings would most likely experience severe overheating after retrofitting. Porritt et al. [5] ranked the interventions to reduce overheating risk during heat waves, and found that the solar gains through windows and the building fabric during the heating season would be reduced by the installation of fixed shading or by coating external surfaces with solar reflective paints.

Figueiredo et al. [6] did sensitivity analysis on the passive house concept under the Portuguese climate. They found that a reduction at a level of respectively $62 \%, 72 \%$ and $44 \%$ for the heating demand, cooling demand, and overheating rate could be achieved when the passive house concept was applied under the Portuguese climate.

\footnotetext{
* Corresponding author: zhiyong.tian@ntnu.no
} 
Heracleous et al. [7] carried out the assessment of overheating risk and the impact of natural ventilation in educational buildings of Southern Europe under current and future climate conditions. It was found that natural ventilation alone could achieve a reduction of overheating hours where operative temperature exceeded the Chartered Institution of Building Services Engineers (CIBSE) maximum limits. The overheating hours can decrease by $28-35 \%$ in 2050 s and by $9-11 \%$ in 2090 s when natural ventilation was used. Psomas et al. [8] analysed the overheating risk barriers to energy renovations of a single family house in Denmark. It was suggested that the increase of the ventilation rates and the use of shading systems were the useful measures for preventing overheating risk.

Mitchell et al. [9] did analysis on the overheating risk in passive dwellings. It was found that in highly insulated dwellings overheating should be considered for individual rooms rather than at whole-dwelling level.

Mlakar et al. [10] investigated solutions to tackle overheating in a residential passive house. They found that windows-opening during the night-time in hot summer days, strict shading of the southern and western windows as well as minimization of internal energy sources were necessary and sufficient to keep internal temperature on a comfortable level.

Taylor et al. [11] did a simulation study on mapping indoor overheating and air pollution risk modification across the United Kingdom. They found that urban areas had higher numbers of buildings prone to overheating, reduced indoor air pollution levels from outdoor sources, and higher air pollution from indoor sources relative to rural areas, driven largely by variations in building types.

Parker et al. [12] carried out analysis on the future overheating risk in a passive dwelling using calibrated dynamic thermal simulation models. It was suggested that extended periods of window opening could help to avoid overheating in the low-energy dwelling under both existing and future climatic conditions. Tink et al. [13] did experiments in a pair of thermally matched, solid walled houses, located in the UK. One of the pair was retrofitted with internal wall insulation, while the other remained uninsulated. It was shown that the mitigation strategy was effective at reducing the internal temperature in the internally insulated house to a level similar to that observed in the uninsulated house. Fosas et al. [14] discussed the mitigation versus adaptation of the overheating risk on the insulating dwellings. A regression-based and a categorical-based analysis both suggest that insulation played a minor role in overheating even when comparing uninsulated to super insulated buildings. They found that increased insulation levels counteracted overheating in buildings.

Gupta et al. [15] did a lot of analysis of summertime indoor comfort in new-built, retrofitted, and existing UK dwellings. The results showed that despite a relatively cool summer, sufficiently high temperatures were found in a high proportion of dwellings, which were overheated according to the static criteria, although the prevalence of overheating was found to be much lower when assessed by the adaptive method. On the contrary to the results reported by Fosas et al. [14], they found that dwellings with higher levels of insulation experienced overheating twice as frequently as uninsulated dwellings.

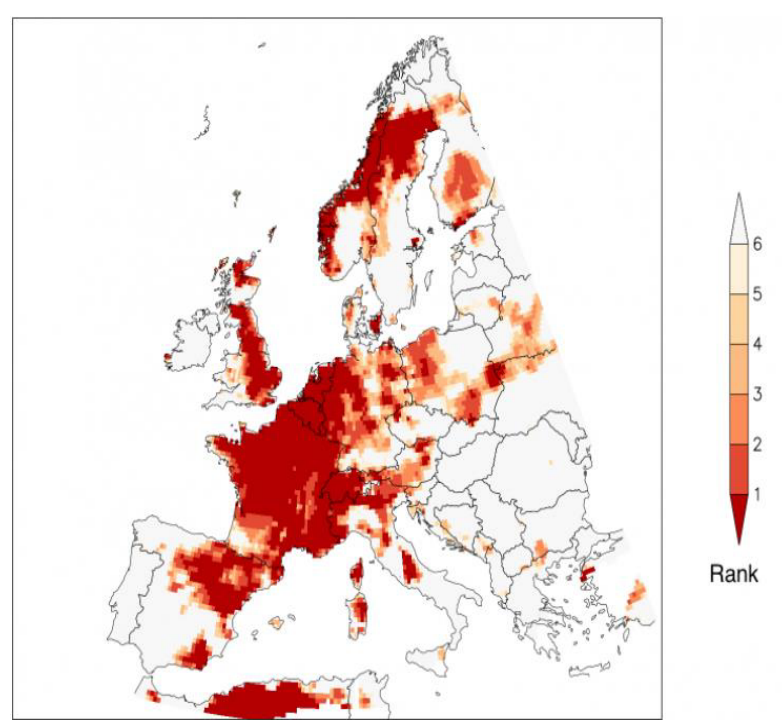

Fig. 1. The rank of annual maximum temperatures observed in Europe in 2019 when compared to 1950-2018, Source: World Weather Attribution.

Figure 1 shows the rank of annual maximum temperatures observed in Europe in 2019 when compared to 1950-2018. In the Figure 1, the dark red indicates that the warmest annual temperature in 2019 is ranked first when compared to 1950-2018. It can be seen that most places of Norway experienced a relatively very hot weather in 2019.

Peacock et al. [16] investigated the potential of overheating in UK dwellings as a consequence of extant climate change. Factors such as a warming climate and varying internal heat gains are estimated to examine whether domestic buildings in UK were likely to be prone to overheating in the future, and therefore require mechanical air conditioning.

High airtightness is required to provide heat savings on required level in the building sector in cold climates and to protect constructions in term of moisture damages. This may indicate that there is a high risk of overheating in the summer months under extreme conditions. As the temperature in the summer period in Norway has usually been moderate, few studies on the indoor comfort of Norwegian residential buildings in the summer seasons were found. Heat waves attacked Norway in recent years. Overheating risk can happen in Norwegian residential buildings without cooling devices installed. Overheating risk of the typical Norwegian residential building retrofitted according to the minimum Norwegian energy requirements in the Norwegian Building Act of 2010 (Pbl2010/TEK17) and the international EnerPHit Standard developed by the Passive House Institute in Darmstadt under three weather scenarios: present-day, the 2050s and the 2080s, were evaluated in this study. 


\section{Method}

Geometry of the typical Norwegian residential building was sketched through Rhinoceros 5 software for Grasshopper. Building performance simulation was carried out in Energy Plus engine via Ladybug and Honeybee plugins from Grasshopper. The typical Norwegian residential building retrofitted to the minimum Norwegian energy requirements (Pbl2010\&TEK17) and the international EnerPHit Standard was modelled in this study. Overheating risk for the typical residential building was simulated by Energy Plus engine via Ladybug and Honeybee plugins.
The present-day EnergyPlus weather format (EPW) was download from the official website. Future weather data (the 2050s and the 2080s) were generated from the HadCM3 were combined with IPCC A2 emission scenario using the morphing method based on the present-day weather file. Three airtight scenarios $(0.0001$ $\mathrm{m}^{3} / \mathrm{s}$ per $\mathrm{m}^{2}$ facade-tight building, $0.0003 \mathrm{~m}^{3} / \mathrm{s}$ per $\mathrm{m}^{2}$ facade-average building, and $0.0006 \mathrm{~m}^{3} / \mathrm{s}$ per $\mathrm{m}^{2}$ facadegeneral building) were investigated in this study.

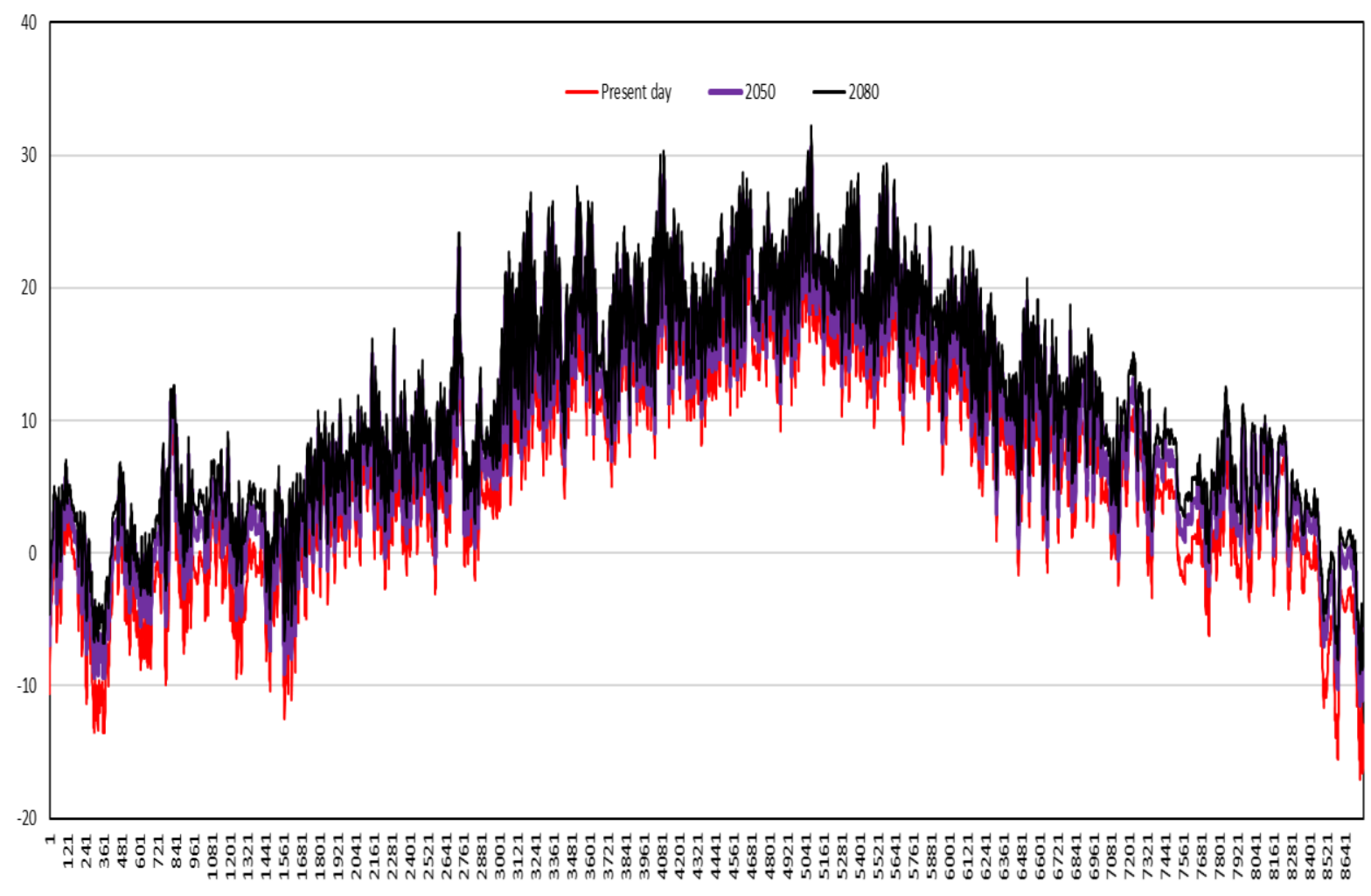

Fig. 2. Hourly ambient temperature $\left({ }^{\circ} \mathrm{C}\right)$ of Oslo in the present-day, 2050s and 2080s.

Figure 2 shows the hourly ambient temperature of Oslo in the present-day, the 2050s and the 2080s. In the present-day, the temperature in summer is below $30{ }^{\circ} \mathrm{C}$. Nowadays, few air conditioners or even electrical fans have been installed in the residential buildings. Two of the simulated scenarios, the 2050s and the 2080s, can be used to simulate conditions of the extreme weather now.

The Passive House Planning Package (PHPP) has been developed by the Passive House Institute in Darmstadt. The PHPP methodology defines the risk of overheating of a building by the frequency when temperatures are calculated to rise above an established comfort limit. The frequency is expressed as a percentage of annual indoor hours. The default limited temperature used in PHPP is $25^{\circ} \mathrm{C}$. The PHI guidelines recommend that when the frequency of temperatures in excess of the comfort limit exceeds $10 \%$ of annual hours, additional summer heat protection measures will be necessary.

\subsection{Typical Norwegian residential building}

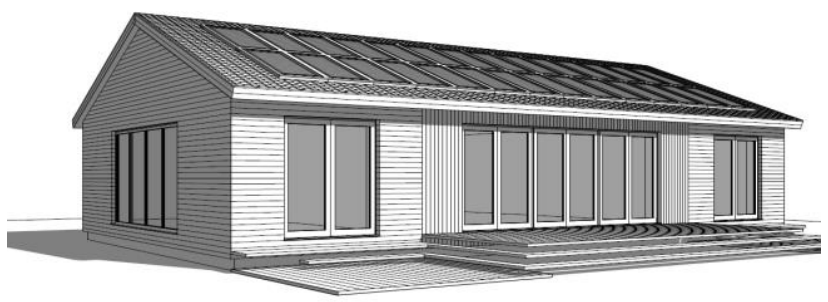

Fig. 3. Typical Norwegian residential building from the 1960s after retrofitting; $120 \mathrm{~m}^{2}$; window-to-wall ratio, WWR 0.35 . 


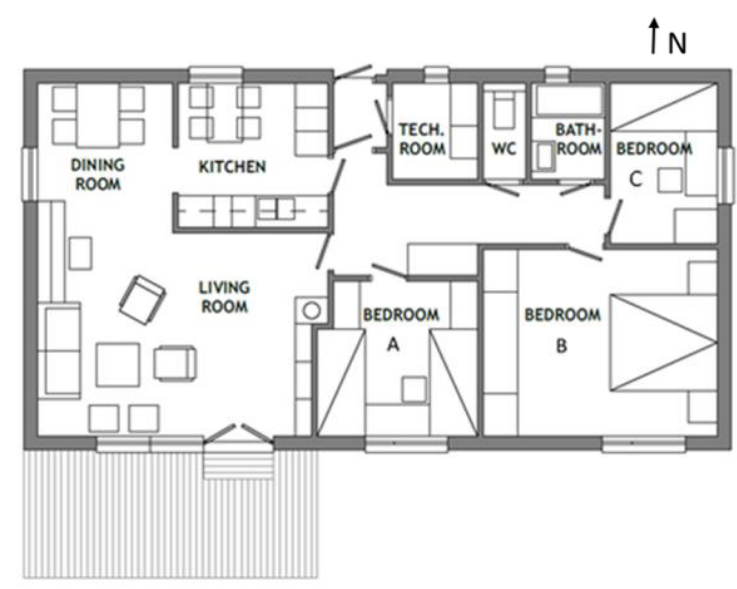

Fig. 4. Layout of the studied building before retrofitting.

Figure 3 shows the simulated building in this study. Figure 4 shows the layout of the building. The area of the studied building was extended from $90 \mathrm{~m}^{2}$ to $120 \mathrm{~m}^{2}$ after retrofitting. Overheating risk for the selected two bedrooms was evaluated. The window-to-wall ratio is the measure of the percentage area determined by dividing the building's total glazed area by its exterior walls area. The WWR is assumed as 0.35 in this study. Three scenarios $\left(0.0001 \mathrm{~m}^{3} / \mathrm{s}\right.$ per $\mathrm{m}^{2}$ facade-tight building, $0.0003 \mathrm{~m}^{3} / \mathrm{s}$ per $\mathrm{m}^{2}$ facade-average building, and $0.0006 \mathrm{~m}^{3} / \mathrm{s}$ per $\mathrm{m}^{2}$ facade-general building) were investigated in this study. Table 1 shows the technical parameters of building envelope components, U-values required/recommended. The window in the TEKscenario consists of insulated frame and two-layer glass with argon in the cavity, with U-value of $1.2 \mathrm{~W} /\left(\mathrm{m}^{2} . \mathrm{K}\right)$, and g-value of 0.61 . The window in the EnerPHitscenario consists of insulated frame and triple-layer glass with argon in the cavity, with U-value of $0.8 \mathrm{~W} /\left(\mathrm{m}^{2} . \mathrm{K}\right)$, and g-value of 0.5 . Maximum allowed U-values for the external walls, the floor, and the roof were used in the analysis.

Table 1. Building envelope components.

\begin{tabular}{cccccc}
\hline & $\begin{array}{c}\text { External } \\
\text { wall }\end{array}$ & $\begin{array}{c}\text { Ground } \\
\text { floor }\end{array}$ & Roof & Window & \\
\hline \multirow{2}{*}{$\begin{array}{c}\text { Thermal } \\
\text { transmittance } \\
\left(\mathrm{W} /\left(\mathrm{m}^{2} . \mathrm{K}\right)\right)\end{array}$} & $\leq 0.22$ & $\leq 0.18$ & $\leq 0.18$ & $\leq 1.2$ & $\begin{array}{c}\text { TEK 17 } \\
\text { (Required } \\
\text { values) }\end{array}$ \\
\cline { 2 - 6 } & $\leq 0.15$ & $\leq 0.15$ & $\leq 0.15$ & $\leq 0.8$ & $\begin{array}{c}\text { EnerPHit } \\
\text { (Recommended } \\
\text { values) }\end{array}$ \\
\hline
\end{tabular}

\section{Results and discussion}

\subsection{Overheating risk analysis}

Overheating hours for the selected two bedrooms were simulated and evaluated in this study. Simulated overheating risk in bedroom $\mathrm{A}$ and bedroom $\mathrm{B}$ were discussed in the section 3.1.1 and 3.1.2, respectively.

\subsubsection{Bedroom A}

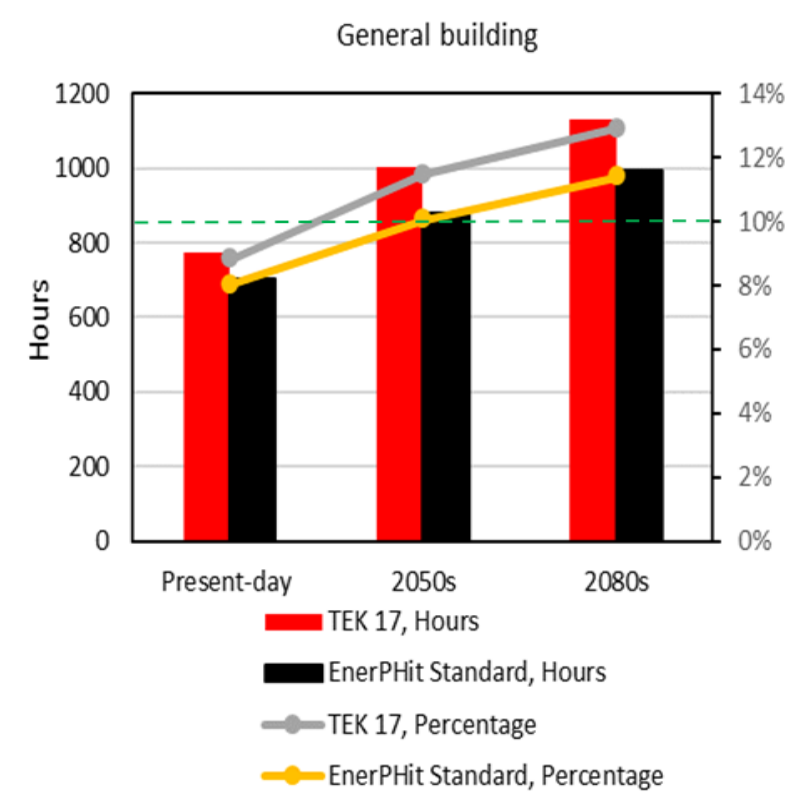

Fig. 5. Annual hours, and percentage, beyond the acceptable temperature of $25^{\circ} \mathrm{C}$ (General building model; Bedroom A).

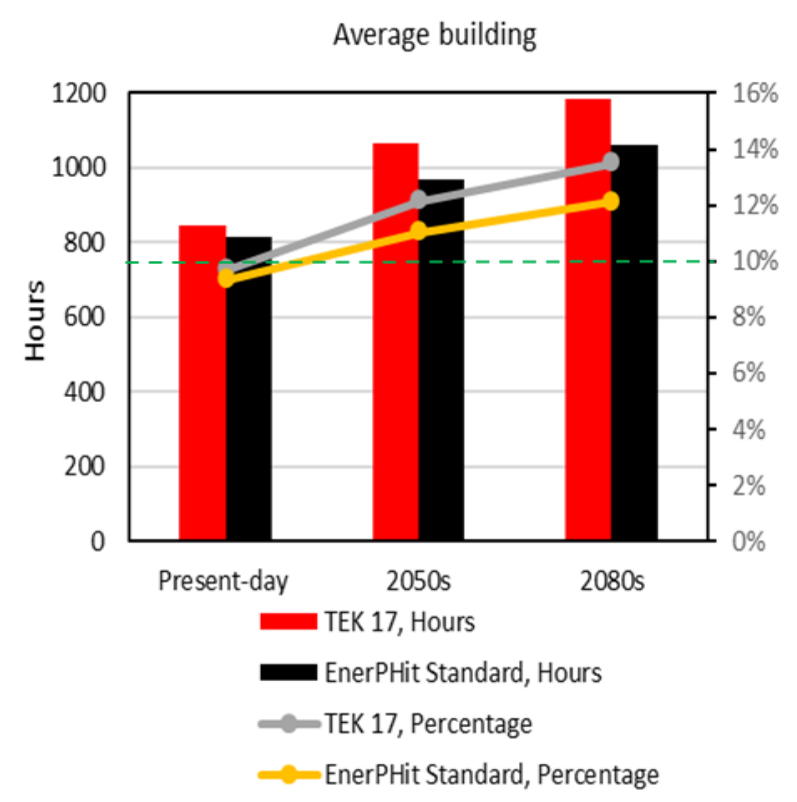

Fig. 6. Annual hours, and percentage, beyond the acceptable temperature of $25^{\circ} \mathrm{C}$ (Average building model; Bedroom A).

Figure 5 shows the total hours beyond $25^{\circ} \mathrm{C}$ for bedroom A (general building model) based on the Norwegian minimum energy requirements in the Pbl2010/TEK17 (criteria for the building envelope components) and the EnerPHit Standard (criteria for the building envelope components). The annual number of hours beyond $25^{\circ} \mathrm{C}$ is less than 800 hours for both the TEK17 and the EnerPHit scenarios under the presentday weather conditions. Under the future weather conditions, the 2050 s and the 2080 s, the annual number of hours beyond $25^{\circ} \mathrm{C}$ is much more than 876 hours (more than 10\%) for all the scenarios, except the 
EnerPHit-scenario for the 2050s (general building model). The decrease on the unacceptable hours for the EnerPHit-scenario compared to the TEK17-scenario is 69 hours under present-day weather condition. The decrease on the unacceptable hours for the EnerPHitscenario compared to the TEK17-scenario is 124 hours under future, the 2050s, weather conditions. The decrease on the unacceptable hours for the EnerPHitscenario compared to the TEK17-scenario is 134 hours under future, the 2080s, weather conditions. From the results for these three weather scenarios, it can be seen that the building retrofitted according to the EnerPHit Standard has more advantages to avoid overheating risk under the future extreme weather conditions compared to the building retrofitted according to the TEK17.

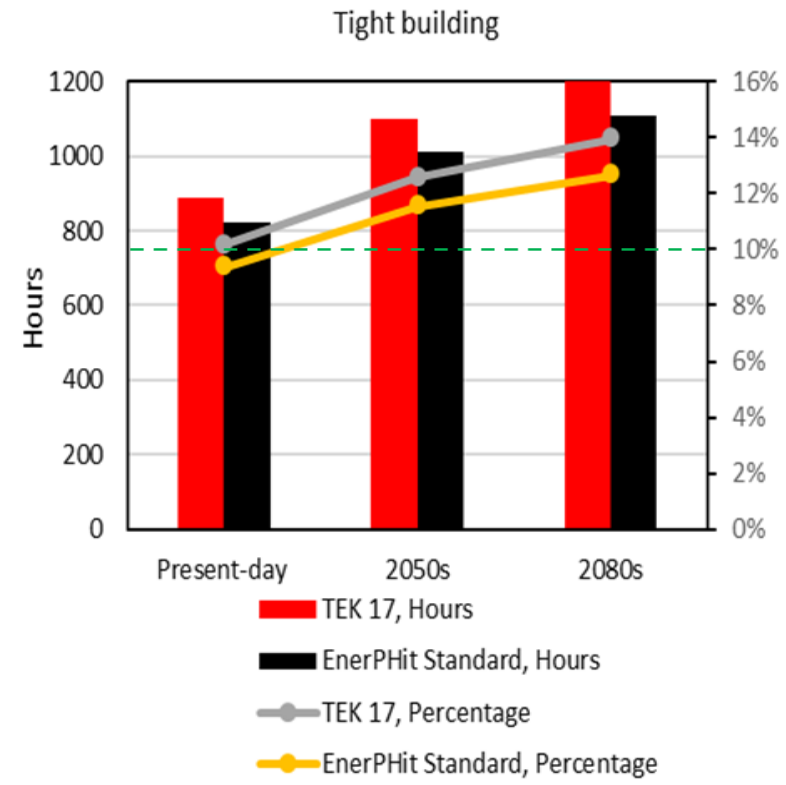

Fig. 7. Annual hours, and percentage, beyond the acceptable temperature of $25^{\circ} \mathrm{C}$ (Tight building model; Bedroom A).

Figure 6 shows the total number of hours beyond $25^{\circ} \mathrm{C}$ of bedroom A (average building model) based on the Norwegian minimum energy requirements in the Pb12010/TEK17 (criteria for the building envelope components) and the EnerPHit Standard (criteria for the building envelope components). Compared to the general building model, the number of unacceptable hours in the average building model increases by 50-100 hours. Similarly to the general building model, all the scenarios under future, the 2050s and the 2080s weather conditions, have more than 876 unacceptable hours (more than 10\%), except the scenarios under the presentday weather conditions.

Figure 7 shows the total number of hours beyond $25^{\circ} \mathrm{C}$ of bedroom A (tight building model) based on the Norwegian minimum energy requirements in Pbl2010/TEK17 (for the building envelope components) and the EnerPHit criteria (for the building envelope components). Compared to the average building model, the unacceptable number of hours in the tight building model increases by about 50 hours.

As shown in the Figure 5, Figure 6 and Figure 7, better insulation can reduce the number of unacceptable hours slightly in all the scenarios. It also can be seen that the general building model (least tight) has the least number of unacceptable hours compared to the average building and to the tight building. Less airtightness results in less overheating. Better insulated but less tight buildings tend to have lower overheating risk. Then, it can be concluded that natural ventilation could be one of the good solutions to reduce overheating.

\subsubsection{Bedroom B}

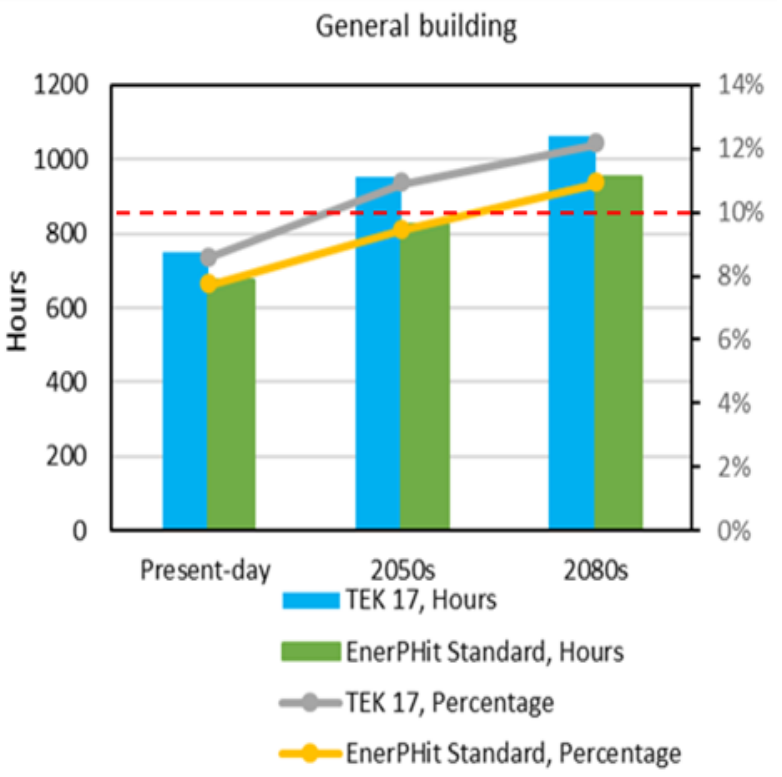

Fig. 8. Annual hours, and percentage, beyond the acceptable temperature of $25^{\circ} \mathrm{C}$ (General building model; Bedroom B). Average building

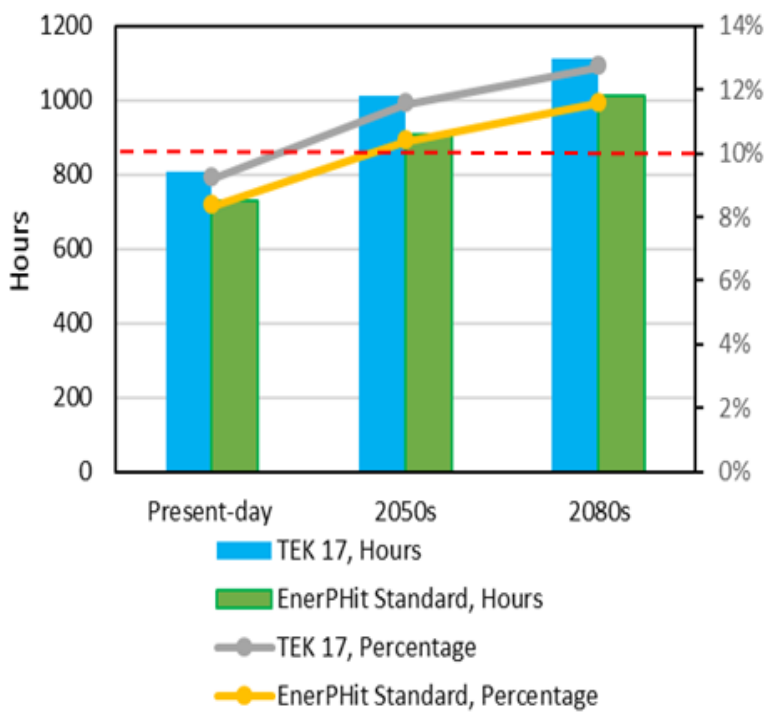

Fig. 9. Annual hours, and percentage, beyond the acceptable of $25^{\circ} \mathrm{C}$ (Average building model; Bedroom B).

Figure 8 shows the total number of hours beyond $25^{\circ} \mathrm{C}$ for bedroom B (general building model) based on the Pb12010/TEK17 (criteria for the building envelope components) and the EnerPHit Standard (criteria for the building envelope components). The total number of 
hours beyond $25^{\circ} \mathrm{C}$ for the bedroom $\mathrm{B}$ based on the TEK17 is, 750 hours, 954 hours and 1061 hours under respectively the present-day, the 2050 s and the 2080 s weather conditions. The total number of hours beyond $25^{\circ} \mathrm{C}$ for the bedroom B based on the EnerPHit Standard is, 674 hours, 826 hours and 953 hours under respectively the present-day, the 2050 s and the 2080 s weather conditions.

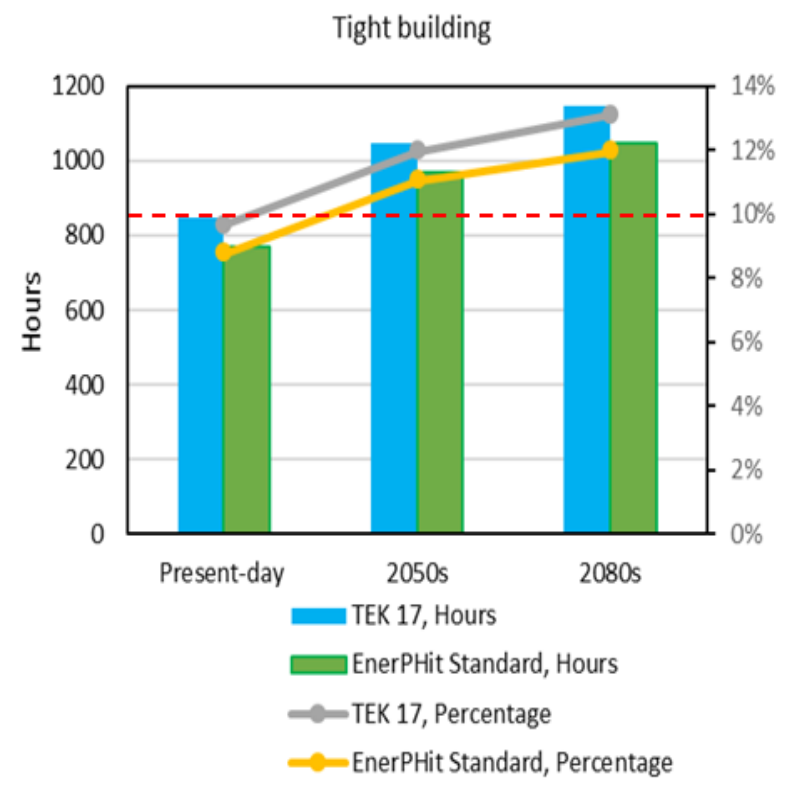

Fig. 10. Annual hours, and percentage, beyond the acceptable temperature of $25^{\circ} \mathrm{C}$ (Tight building model; Bedroom B).

Figure 9 shows the total number of hours beyond $25^{\circ} \mathrm{C}$ for the bedroom B (average building model) based on the Pbl2010/TEK17 (criteria for the building envelope components) and the EnerPHit Standard (criteria for the building envelope components). The total number of hours (average building model) beyond $25^{\circ} \mathrm{C}$ for the bedroom B increases by about 50-80 hours, compared to the general building model.

Figure 10 shows the total number of hours beyond $25^{\circ} \mathrm{C}$ for the bedroom B (tight building model) based on the Pbl2010/TEK17 (criteria for the building envelope) and the EnerPHit Standard (criteria for the building envelope). The total number of hours (tight building model) beyond $25^{\circ} \mathrm{C}$ for the bedroom $\mathrm{B}$ increases by about 30-60 hours, compared to the average building model.

It was similarly found that better insulation can reduce the number of unacceptable hours slightly. In the section 3.1.1 and 3.1.2, it can be found that the number of unacceptable hours is less than $10 \%$ of total hours (876-hours) under the present-day conditions, except the TEK 17 for bedroom A (tight building model). However, under the future weather conditions, such as the 2050s and the 2080s, the overheating hours of most scenarios are more than $10 \%$ of the total hours. It shows that overheating can happen in the near future. As overheating risk tends to become a common problem in the Norwegian residential buildings, it should be paid more attention already now. Night ventilation and solar shading solutions are needed to be taken into consideration when existing buildings are retrofitted to higher energy standards.

\subsection{Energy saving potential}

In addition to reduction of the number of unacceptable hours, buildings retrofitted according to higher energy standards as the EnerPHit Standard has potential to decrease significantly their heating demand. The cooling demand seems not to be a crucial problem in the Norwegian context, in the near future. However, building envelopes with window-to-wall ratio (WWR) above a level of 0.4 should be avoid already now [17]. Better insulation means less heat losses in the winter seasons. The heating demand based on the EnerPHit Standard (criteria for the building envelope components represented by U-value) is about $30 \%$ lower than that based on TEK 17 (criteria for the building envelope components represented by U-values).

\section{Conclusion}

The simulation on indoor comfort of the typical Norwegian residential building retrofitted to the higher energy standards was carried out. Overheating risk of the selected two bedrooms was evaluated. The number of unacceptable hours of the studied rooms under the present-day, the 2050 s and the 2080 s weather conditions was found. Three scenarios $\left(0.0001 \mathrm{~m}^{3} / \mathrm{s}\right.$ per $\mathrm{m}^{2}$ facadetight building, $0.0003 \mathrm{~m}^{3} / \mathrm{s}$ per $\mathrm{m}^{2}$ facade-average building, and $0.0006 \mathrm{~m}^{3} / \mathrm{s}$ per $\mathrm{m}^{2}$ facade-general building) were investigated in this study. Better insulation can reduce the number of unacceptable hours of the analysed bedrooms slightly which aligns with the empirical evidence [18]. Low g-value of the window in the EnerPHit-scenario also contributed to the reduction of the number of unacceptable hours. The use of improved insulation levels in the analysed scenarios was found not sensible to increase overheating hours. Too good airtightness, on the contrary, increased the overheating risk when the building was retrofitted to higher energy standards. Overheating issues should be paid attention already now and due to the expected climate change. Natural night ventilation and solar shading should be considered additionally when an existing building is considered to be retrofitted.

For the one thing, the typical Norwegian residential building retrofitted to the international EnerPHit Standard can provide lower overheating risk than that retrofitted to the minimum Norwegian energy requirements in the Norwegian Building Act of 2010 (Pbl2010/TEK17). Besides, the heating demand of the typical Norwegian residential building retrofitted to the international EnerPHit Standard is lower. Thus, the international EnerPHit Standard or a similar Norwegian Standard for existing buildings is suggested to be implemented in Norway in the near future. 
The authors would like to acknowledge the Norwegian University of Science and Technology (NTNU), the Faculty of Engineering and the Department of Civil and Environmental Engineering for financial support of the research.

\section{References}

1. Vandentorren, S.; Bretin, P.; Zeghnoun, A.; Mandereau-Bruno, L.; Croisier, A.; Cochet, C.; Ribéron, J.; Siberan, I.; Declercq, B.; Ledrans, M. August 2003 Heat Wave in France: Risk Factors for Death of Elderly People Living at Home. European Journal of Public Health 2006, 16, 583591.

2. Li, X.; Taylor, J.; Symonds, P. Indoor overheating and mitigation of converted lofts in London, UK. Building Serv. Eng. Res. Technol 2019, 40, 409425.

3. Grussa, Z. De; Andrews, D.; Lowry, G.; Newton, E.J.; Yiakoumetti, K.; Chalk, A.; Bush, D. A London residential retrofit case study: Evaluating passive mitigation methods of reducing risk to overheating through the use of solar shading combined with night-time ventilation. Building Services Engineering Research and Technology 2019, 40, 389-408.

4. Salem, R.; Bahadori-Jahromi, A.; Mylona, A. Investigating the impacts of a changing climate on the risk of overheating and energy performance for a UK retirement village adapted to the nZEB standards. Building Serv. Eng. Res. Technol 2019, 40, 470-491.

5. Porritt, S.M.; Cropper, P.C.; Shao, L.; Goodier, C.I. Ranking of interventions to reduce dwelling overheating during heat waves. Energy and Buildings 2012, 55, 16-27.

6. Figueiredo, A.; Figueira, J.; Vicente, R.; Maio, R. Thermal comfort and energy performance: Sensitivity analysis to apply the Passive House concept to the Portuguese climate. Building and Environment 2016, 103, 276-288.

7. Heracleous, C.; Michael, A. Assessment of overheating risk and the impact of natural ventilation in educational buildings of Southern Europe under current and future climatic conditions. Energy 2018, 165, 1228-1239.

8. Psomas, T.; Duer, K.; Bjørn, E. Overheating risk barriers to energy renovations of single family houses: Multicriteria analysis and assessment. Energy and Buildings 2016, 117, 138-148.

9. Mitchell, R.; Natarajan, S. Overheating risk in Passivhaus dwellings. Building Services Engineering Research and Technology 2019, 40, 446-469.

10. Mlakar, J.; Strancar, J. Overheating in residential passive house: Solution strategies revealed and confirmed through data analysis and simulations. Energy \& Buildings 2011, 43, 1443-1451.

11. Taylor, J.; Davies, M.; Mavrogianni, A.; Shrubsole, C.; Hamilton, I.; Das, P.; Jones, B.; Oikonomou, E.; Biddulph, P. Mapping indoor overheating and air pollution risk modification across Great Britain: A modelling study. Building and Environment 2016, 99, 1-12.

12. Parker, J.; Fletcher, M.; Johnston, D. Predicting future overheating in a passivhaus dwelling using calibrated dynamic thermal simulation models. In Building Information Modelling, Building Performance, Design and Smart Construction; 2017; pp. 163-183 ISBN 9783319503462.

13. Tink, V.; Porritt, S.; Allinson, D.; Loveday, D. Measuring and mitigating overheating risk in solid wall dwellings retrofitted with internal wall insulation. Building and Environment 2018, 141, 247-261.

14. Fosas, D.; Coley, D.A.; Natarajan, S.; Herrera, M.; Fosas de Pando, M.; Ramallo-Gonzalez, A. Mitigation versus adaptation: Does insulating dwellings increase overheating risk? Building and Environment 2018, 143, 740-759.

15. Gupta, R.; Gregg, M.; Irving, R. Meta-analysis of summertime indoor temperatures in new-build, retrofitted, and existing UK dwellings. Science and Technology for the Built Environment 2019, 25, 1212-1225.

16. Peacock, A.D.; Jenkins, D.P.; Kane, D. Investigating the potential of overheating in UK dwellings as a consequence of extant climate change. Energy Policy 2010, 38, 3277-3288.

17. Hrynyszyn, B.D.; Tian, Z. Solutions for retrofitting existing, wooden houses in cold climates, Nordic Symposium on Building Physics, NSB2020, Tallinn, Estonia, (to be published).

18. Fosas, D.; Coley, D.A.; Natarajan, S.; Herrera, M.; Fosas de Pando, M.; Ramallo-Gonzalez, A. Mitigation versus adaptation: Does insulating dwellings increase overheating risk? Building and Environment 2018, 143, 740-759. 